\title{
Environmental determinism and archaeology. Understanding and evaluating determinism in research design
}

\author{
V. P. J. Arponen, ${ }^{1 *}$ Walter Dörfler, ${ }^{2}$ Ingo Feeser, ${ }^{3}$ Sonja Grimm, ${ }^{4}$ Daniel Groß, ${ }^{5}$ Martin Hinz, ${ }^{6}$ \\ Daniel Knitter, ${ }^{7}$ Nils Müller-Scheeßel, ${ }^{8}$ Konrad Ott ${ }^{9}$ and Artur Ribeiro ${ }^{10}$ \\ ${ }^{1}$ University of Kiel, SFB 1266, Leibnizstr. 3, 24118 Kiel, Germany, ${ }^{2}$ University of Kiel, Institute of Pre- and Protohistoric \\ Archaeology, Johanna-Mestorf-Str. 2-6, 24118 Kiel, Germany, ${ }^{3}$ University of Kiel, Institute of Pre- and Protohistoric \\ Archaeology, Johanna-Mestorf-Str. 2-6, 24118 Kiel, Germany, ${ }^{4}$ Center for Baltic and Scandinavian Archaeology, Stiftung \\ Schleswig-Holsteinische Landesmuseen Schloss Gottorf, 24837 Schleswig, Germany, ${ }^{5}$ Center for Baltic and Scandinavian \\ Archaeology, Stiftung Schleswig-Holsteinische Landesmuseen Schloss Gottorf, 24837 Schleswig, Germany, ${ }^{6}$ University of \\ Bern, Institut für archäologische Wissenschaften, Prähistorische Archäologie (Ur- und Frühgeschichte) and Oeschger \\ Centre for Climate Change Research (OCCR), Mittelstrasse 43, 3012 Berne, Switzerland, ${ }^{7}$ University of Kiel, Department \\ of Geography, Physical Geography, Christian-Albrechts-Universität zu Kiel, Ludewig-Meyn-Str. 14, 24118 Kiel, Germany, \\ ${ }^{8}$ University of Kiel, Institute of Pre- and Protohistoric Archaeology, Johanna-Mestorf-Str. 2-6, 24118 Kiel, Germany, \\ ${ }^{9}$ University of Kiel, Department of Philosophy, Leibnizstr. 6, 24118 Kiel, Germany and ${ }^{10}$ University of Kiel, SFB 1266 , \\ Leibnizstr. 3, 24118 Kiel, Germany \\ *Corresponding author. Email: varponen@gshdl.uni-kiel.de
}

\begin{abstract}
With the emergence of modern techniques of environmental analysis and widespread availability of accessible tools and quantitative data, the question of environmental determinism is once again on the agenda. This paper is theoretical in character, attempting, for the benefit of drawing up research designs, to understand and evaluate the character of environmental determinism. We reach three main conclusions: (1) in a typical pattern of research design, studies seek to detect simultaneous shifts in the environmental and archaeological records, variously positing the former to have influenced, triggered or caused the latter; (2) the question of determinism involves uncertainty about the justification for the above research design in particular in what comes to biologism and the concept of environmental thresholds on the one hand and the externality of the drivers of transformation in human groups and societies on the other; (3) adapting the concepts of the social production of vulnerability and the social basis of hazards from anthropology may help to clarify the available research design choices at hand.
\end{abstract}

Keywords: Agency; anthropology of hazard; palaeo-environmental; vulnerability; resilience; causality

\section{Introduction}

Determinism, in particular environmental determinism, is a recurring topic of debate in modern archaeology and related disciplines (Meggers 1954; 2001; Wheatley 1993; Contreras 2016; Middleton 2017; Bicho and Cascalheira 2018). The issue of determinism has become more prominent in recent years, partly due to the rise and dissemination of new scientific techniques in archaeology, such as ancient DNA (aDNA) and isotope analysis that have been argued to 'open up a new chapter in archaeological knowledge that demand similar changes in archaeological methods and theory' (Kristiansen 2014, 12). These new techniques have fomented a desire to return to the questions and topics promoted in processual archaeology (e.g. Kintigh et al. 2014) motivated by the belief that the archaeological problems which could not be addressed thirty 
or forty years ago might now be addressable by new scientific methods. Most noticeable has been the strong resurgence of palaeo-environmental studies. In the background of academic debate, the worsening contemporary environmental situation adds its own colour to the discussion.

It seems fair to say that, at its core, determinism in archaeology and related disciplines has been a term of reproach. To speak of environmental determinism involves the contrast between understanding, explaining and describing prehistoric human action as a response or reaction to, and thus as it were determined by, environmental factors as opposed to studying the various cultural and social factors affecting the course of human (pre)history. Processual archaeology is sometimes taken to be advocating deterministic models of human behaviour, while postprocessual archaeology, by contrast, is taken to advocate the study of the contingency of historical events (Hodder 1985) or the agency of actors to produce non-deterministic behaviour (Dobres and Robb 2000). In the words of Ian Hodder,

It is argued by the processual school in archaeology that there are systems so basic in nature that culture and individuals are powerless to divert them. This is a trend towards determinism - theory building is seen as being concerned with discovering deterministic causal relationships. There is a close link here between discarding notions of cultural belief and of agency (Hodder and Hutson 2003, 7).

Although archaeology has in many ways moved on beyond the ideas espoused by processual and postprocessual archaeology, archaeological research is still commonly framed as either deterministic or non-deterministic. Broadly speaking, argued Elizabeth Arkush (2011, 200), 'our differences lie in the extent to which we stress contingency versus process, and agency versus conditions, in the making of diverse human histories'.

In the background to the contrast looms the larger, antagonistic 'two-cultures' debate (Snow 1998). The perception is that, modelled on the natural sciences, hard and proper scientific sciences ought to be concerned with causal relationships whereas softer, interpretive sciences generally fall short of that or, alternatively, must be conceived as reaching for some wholly different kinds of conclusions altogether - comparative or exploratory, perhaps (Sørensen 2017). The focus on the study of the impact of natural systems on human behaviour is often a methodological choice springing, on the one hand, from disciplinary preferences relating to the dominant or emerging paradigms (Kuhn 1996; Lucas 2017) or controlling models (Clarke 1972). The practical disciplinary reality of archaeology often plays its own role: the availability of particular kinds of often sparse data - and the fact that, in certain contexts, environmental data is the easier, or the only, one to come by.

Not only does the most recent palaeo-environmental work proclaim itself to be aware of the charge of environmental determinism and explicitly aim for more balanced accounts of the past, but there is also growing awareness of the distinction between identifying causal as opposed to probable or correlative connections (see e.g. Contreras 2016; Faulseit 2015; Coombes and Barber 2005). In philosophy and social theory, there exists a long-standing debate regarding the best way to conceive the kinds of knowledge that the human sciences, as opposed to natural sciences, are trying to attain: whether the human sciences, too, ultimately deal with causal facts - albeit disguised beneath a layer of so-called emergent phenomena - or whether both, the natural and the human sciences, actually are best conceived of as not dealing with causal facts at all (Dilthey 2008; von Wright 1971; Elder-Vass 2010; Lohse 2017). The indications are, accordingly, that an exploration of the core of the determinism debate will turn out to concern at least as much the selfreferential foundations of our own scientific conduct as the causal foundations of prehistoric transformations. Critical self-reflection about the way we construe our own scientific practices is essential for scientific progress and should not be taken to automatically yield a social-constructivist position (Shennan 1994, Introduction; Bhaskar 2008). 
We write as an interdisciplinary team of researchers working in a joint research project, and we are interested in gaining clarity about what it might mean, if anything at all, to be a determinist. Indeed, as soon as we set off to discuss the topic, we began to suspect that 'determinism' might be one of those catchphrases that carry much emotional baggage and diverse associations, but of which the precise meaning and implications are far harder to articulate.

In what follows we shall begin with a philosophical discussion of the problem and the concept of determinism. This will lead to us making explicit a typical form of reasoning that is commonly found in palaeo-environmental research in archaeology - one that is typically oriented to detecting certain parallels between societal and environmental changes. We will also discuss blind spots and potential problems with this form of reasoning. We conclude with thoughts on how the social aspects of the human-environment relationship could be brought into sharper focus in the studies that build upon said parallels. In our view, the study of environmental or climate triggers, influences or even causes of societal processes is understood as a rigorous research practice focused on empirical questions and data. Environmental determinism is not an a priori faulty form of structuring research design. That said, such studies typically draw from paradigms or controlling models that have their own weaknesses and blind spots, as we observe with reference to selected literature below. Such weaknesses and blind spots might be said to reflect a deterministic orientation, yet the issue is ultimately empirical.

\section{The philosophical problem of determinism}

The classic philosophical problem of determinism arises as follows. It starts off from the conviction that the modern natural scientific world view is in its fundamental aspects correct, namely that physical reality is a totality of physical 'elements' in the broad sense as these are revealed to us by the theories of physics, biology and so forth. It also belongs to this picture that these 'elements' interact in ways that are regular and law-governed; that is, that there are such things as laws of nature that govern the behaviour of the 'elements' which are studied in the respective sciences. To introduce further terminology, these interactions can be called chains of causes and effects that make up the causal world with a certain causal history. Such a picture comprehensively and exhaustively describes 'the real', the reality, the world or the universe, past and present. In philosophical discourse, such a picture is often referred to as the materialist or the physicalist picture.

Now, from this physicalist conviction alone the philosophical problem of determinism already follows, for in physicalism, any worldly processes, including human decisions and actions, can only be further links in the chain of causes and effects and therefore determined by the state of the antecedent universe. This 'can only be' is a highly significant expression because in the physicalist picture, anything that falls outside the chain of causes and effects is either non-existent or irrelevant to the chain (as it does not affect the chain). It is unreal.

In a somewhat neglected paper, the archaeologist Travis W. Stanton (2004) provides an excellent and nuanced analysis of the situation, arguing that, understood as a causal position, determinism can basically only offer incomplete and selective accounts of the causal reality it purports to describe. Stanton takes it that environmental determinism makes causal claims about the world and, as such, Stanton's perhaps surprising view is that determinism as we might find it, for example, in palaeoclimatology is not deterministic enough, or, better said, it is incompletely deterministic (ibid., 7 and passim).

Stanton's view can be understood as setting off from the physicalist picture and the view that for each event an astonishing array of multiple causes are or were at work. Of this array, even our best deterministic theories can only ever hope to grasp, understand and formulate a small fraction. In practice, Stanton argues, most theories focus on very few causes; that is, they are monocausal, or they are what is only slightly better, multicausal (ibid., 36). In either case, our accounts of the 
events can only remain hopelessly incomplete in the face of the immense causal complexity of reality itself.

\section{Thresholds and biologism}

Most palaeo-environmental scientists would probably be sympathetic to Stanton's argument and make an admission along the lines of the palaeo-ecologists Coombes and Barber, saying, 'Of course, a model cannot hope to reproduce all the processes and interactions in a particular culture'. That said, many would perhaps also make the caveat that Coombes and Barber go on to make, that 'a representation of the system's critical components should be feasible' (Coombes and Barber 2005, 305). That is,

A simple model cannot hope to replicate all the complexities of environment-culture relationships across a civilization, but one basic approach that can provide valuable insights is to treat human populations in ecological terms, with their ranges shifting in response to changing conditions (ibid.).

Coombes and Barber articulate here a basic, widely shared approach to human-environment relations: the environment sets the frame or thresholds within which human groups exist, with changes to critical parts of the frame inevitably affecting the humans living within it. As a consequence, palaeo-environmental studies are frequently structured as investigations into shifts in environmental thresholds that are then related to parallel, simultaneous, changes in archaeological proxies such as those detecting the extent of human occupation in a given area. That is to say, palaeo-environmental research designs are typically structured such as to observe shifts that occur, in tandem, in the archaeological record on the one hand and in some environmental and/or climate record on the other.

The basic logic behind such parallelism is certainly plausible. There is a baseline of biologism built into modern reasoning about human existence - the view that, whatever else, human life is fundamentally a biological phenomenon and humans are therefore subject to biological conditions and needs. The biological needs are satisfied in the frame of available environmental affordances and, by implication, changes in environmental thresholds will affect all biological creatures living within them.

It is of no use to employ such contested labels as 'environmental determinism' here, but it seems fair to say that the determinism debate is fuelled by a particular uncertainty about the idea of biologism and thresholds: on the one hand, the biologistic idea of the climate and environmental thresholds being fundamental to human existence is eminently plausible, yet, on the other hand, many also feel that the picture overtly and unduly externalizes the drivers of change in human societies. Great potential for conflict - and arguably the gist of the determinism debate - exists precisely where, along the continuum from external influence to internal societal dynamics, to locate the moving forces of prehistoric transformations. In what follows, we discuss the issue further with selected examples from palaeo-environmental archaeology.

\section{The tightness of thresholds}

Consider the conclusion to a paper discussing, on the basis of high-resolution records of stable carbon and oxygen isotopes in ostrich, faunal and shellfish remains from the Middle Stone Age of southern Africa, the climate-change-based explanations of 'the emergence of innovative behaviours'. Roberts et al. $(2016,16)$ argue that '[i]t seems that although climatic and environmental change clearly occurred in this region, a diversity of potential resources allowed human 
populations to absorb these changes'. There is, therefore, the question of how tight particular environmental thresholds envelope human life such that changes in the thresholds will elicit a human response. Roberts et al. would presumably also accept biologism as a basic tenet of scientific thinking about human existence, yet the precise way the thresholds impinge upon human life is still up for debate. At its heart, the question of determinism thus remains an empirical question, not an a priori charge levelled against a particular study.

The tightness of the thresholds is again a topic in another study from a different prehistoric context. Jones et al. $(1999,138)$ provide extensive observations and arguments for the general view 'that the linkages between the physical/biotic environment and human subsistence and settlement are sufficiently tight to warrant serious consideration of environmental change as a potentially important factor in explanations of cultural change'. Their archaeological case studies focus on North America and their more specific contention is that

the interval between A.D. 800 and 1350, known to climatologists alternatively as the Medieval Warm Period, the Secondary Climatic Optimum, the Little Optimum ... or the Medieval Climatic Anomaly ... was a time of increased aridity that coincided with a unique pattern of demographic stress and frequent economic crises across much of Western North America (ibid.).

As a result, Jones et al. (ibid.) continue, 'Large populations of agriculturalists and hunter-gatherers were confronted with serious and abrupt declines in productivity caused by repeated and prolonged droughts'. Extensive case study materials are offered to support the general view that the climatic and environmental changes in question 'can and did cause cultural changes in the prehistoric past, and attribution of cause to environment in archaeological models need not be deterministic' (ibid.).

However, at the end of the paper, a range of specialists provide comments to the main article. Pertaining to our present point regarding thresholds, one commentator points out,

A key problem here [in Jones et al. 1999] is that in almost none of the cases mentioned do we have anything like a clear understanding of precisely what is actually limiting population. There is certainly a basic connection between population and food supply, but the relationship is seldom direct and cannot simply be assumed to be so (Robert L. Bettinger in Jones et al. 1999, 158).

The commentator goes on to suggest that it is 'unlikely ... that drought would have had a uniformly adverse effect on all food sources of interest', as well as that 'drought may well create as many exploitative opportunities as it destroys' (Robert L. Bettinger in ibid., 159; see also Bettinger, Garvey and Tushingham 2015). We are aware that we are providing here just one selected criticism of Jones et al. Yet, again, as in the context of Roberts et al. (2016) above, the criticism levelled against Jones et al. (1999) indicates that the issue of thresholds is an empirical question that ought to be acknowledged to exist and addressed in an empirical manner in our research designs.

At the core of the research design in Jones et al. we find the aforementioned parallelism: parallel, simultaneous, shifts in the archaeological record ('a unique pattern of demographic stress and frequent economic crises') and the environmental thresholds ('the medieval climatic anomaly') are detected and used on the basis of an argument positing a relationship between them - in this case the verb 'cause' is used. Bettinger's critique challenges whether sufficient empirical evidence is presented and/or is available to support the conclusion of Jones et al.

Once again in a parallel critique, Grattan $(2006,11)$ argued that, while ' $[w]$ ithin the Holocene there are many volcanic eruptions coincident with climatic and/or cultural change', there 
apparently still is room for debate as, according to Grattan, 'the precise mechanism by which one could have influenced the other is obscure and a clear tendency exists to simply assume that the eruption and subsequent climate change was [sic] large enough to have triggered the coincident environmental or cultural change'. The observation made by Grattan here is strikingly analogous to Bettinger's note quoted above that the relationship between changes in climate and their effects upon people is 'seldom direct and cannot simply be assumed to be so'.

Again, a strikingly similar observation was made in the context of Andean prehistory, and the case of the 300-year drought from A.D. 1150 onwards faced by the Tiwanaku state, by Clark L. Erickson (1999). Erickson critically reviewed what he referred to as 'neo-environmentalist' accounts (citing e.g. Binford et al. 1997 and papers in Kolata 1993) of how 'cultural change could be explained by climatic shifts in rainfall and temperature' (Erickson 1999, 634). We do not have to go into details of the case here, but Erickson's general argument is that while the neo-environmentalists had viewed the drought as bringing the populations of the area across their environmental thresholds, Erickson argued that in fact these people were accustomed to dealing with such environmental phenomena: 'Peoples inhabiting the lake region have developed a complex indigenous knowledge system that includes a sophisticated agricultural technology and elaborate social strategies to mitigate both short- and long-term climatic fluctuations' (ibid., 641).

One of the examples given by Erickson here concerns the effects of prolonged drought on the water level of Lake Titicaca. Erickson explained that while a drought could have obvious adverse effects on agriculture, in fact the receding water exposed 'deep, organic-rich soil that is highly prized by local farming communities'. While others inevitably suffered from droughts, Erickson continued, 'the communities who control lakeshore territories managed to become "rich" during the droughts by selling the abundant surplus produced on newly exposed lake bed and renting those lands to those less fortunate' (ibid., 637). Therefore, again, the relationship between environmental impacts and social changes is seldomly direct. What kind of disaster a drought would wreak upon the wider area would thus arguably depend on the social and political systems in place in terms of which the changes are, or indeed are not, dealt with - more on this below.

Based on the above cases, thinking about the human relationship with the environment in terms of shifting thresholds appears to bear the risk of the shifts being taken as more significant than they were. The brief survey of literature provided above is, of course, not exhaustive, and it is not systematic. Yet, given that the palaeo-environmental research designs are typically built to detect parallel changes in environmental and archaeological proxies, we can expect that such studies can be challenged on the ground of whether the alleged transgressions of the tresholds identified in a given study really constituted real transgressions. The point of our brief survey above is to illustrate that the form of research is in principle - and often in actual fact - vulnerable in that way.

A possible lesson with regard to devising research designs might thus be this: while the detection of parallel shifts in some environmental and cultural proxies might be taken to indicate a relationship, it seems that previous studies have often been challenged precisely on the question whether particular changes in the thresholds are representative enough to carry through the general argument. It is important to note that none of the commentators cited above are challenging the general idea of biologism and that there may be environmental thresholds. They are, rather, calling for greater care in the evaluation of the impacts of changing thresholds.

It seems possible to draw two morals from the story. One moral is that simply greater care is needed to evaluate the ability of shifts in particular thresholds to affect human life. That is a matter of greater care in empirical evaluation and argumentation - and certainly also of the quality and breadth of available data sets.

The other moral is that there may be a systematic, paradigmatic, bias in favour of studies focusing on the detection of parallel shifts in environmental and archaeological proxies such that such parallels appear as a priori plausible, and are therefore easily asserted, then affirmed, in studies. After all, the very form of the research design is oriented to detecting parallel shifts in 
environmental and archaeological proxies, and when such parallels are detected the argument from external influence is easily made. We want to leave it to the reader to pick the moral they find more plausible.

\section{Environment and human agency: the social basis of hazards}

As noted above, a second thread in the discussion about environmental determinism has been the question whether 'environmentally deterministic' accounts afford too minor a role for human agency; that is, whether there is not only an environmental, but also a social, basis to the human-environment relationship. To open up that discussion, let us briefly turn to another case study.

Hoggarth et al. (2016) studied 'the impacts of climate on complex, rainfall-dependent, agricultural societies' with 'multi-decadal droughts' possibly behind the so-called Classic Maya collapse. In a related publication, Hoggarth et al. (2017) describe the severity of the drought episodes by a comparison with documented evidence from the later colonial period from the first quarter of the 18th century onwards. The aforementioned parallelism of the research design is present here as well: shifts in climate proxies are related to parallel shifts in the archaeological record. In addition, Hoggarth et al. (2016) consider further historical, comparative anthropological data from a later period. In their conclusion they posit 'a strong relationship between political disintegration and climatic stress in the Maya lowlands' (ibid., 25), although the word 'cause' is not used. This may be a case in which the impact of the changing environmental thresholds is purely a matter external to the communities affected: the droughts were so severe that the humans could not but come to suffer the consequences.

That said, Hoggarth et al. $(2017,83)$ also state that droughts' 'co-occurrence with other natural and social phenomenon (i.e., locust infestations, epidemics, and warfare)' may greatly amplify the effects of the drought itself. Speaking in terms of the form of the research design, it should be pointed out that in Hoggarth et al. (2017) the parallelistic design is supplemented by a certain autonomy afforded to the social sphere in terms of how the influence of external events plays out in the social world. This takes us on to discuss what we might call the social basis of hazards.

Picking up on the distinction just articulated, there exists a branch of anthropology called the anthropology of hazards and disasters. We bring up this branch of anthropology here not because we ourselves are champions of that perspective, but in order to provide a clearly contrasting picture of how to conceive the human-environment relationship. A recent review article observed, 'Since the 1980s, researchers have focused on concepts of vulnerability, resilience, and adaptation as ways to understand the social bases of disasters' (Peterson and Broad 2016, 74, our italics). In the 1990s, Anthony Oliver-Smith $(1996,304)$, a chief protagonist in this area of academic research, wrote, 'a new perspective has emerged that views hazards as basic elements of environments and as constructed features of human systems rather than as extreme and unpredictable events'.

That is to say, research in this field has proceeded on the assumption that, alongside attention to the effects of changing climate and the environment, societies are affected by changes in their environment because the societies exist in a 'socially and technologically produced condition of vulnerability' (ibid., 303). In particular, the form of decision making prevalent in a society or group is likely to have a great impact on how they deal with an external effect. Peterson and Broad $(2016,76)$ report that 'anthropologists have started to focus on the central role of institutional flexibility for successful adaptation' and on ideas such as that 'inasmuch as climate is a constraint on decision-making, it can also provide an opportunity for creative agency'.

A similar approach drives the work conducted by the United Nations (2016) on poverty and vulnerability to climate change. The UN Climate Change Resilience report observes that the adverse effects of climate change are distributed unevenly, tending to fall specifically upon particular, poorer, regions of the world. Poverty probably is not a useful category for prehistoric purposes. 
However, as the report notes, there are 'structural inequalities that perpetuate poverty, marginalization and social exclusion' (ibid., 4). The report also argues that 'addressing the root causes of inequalities requires transformative policies that generate change in the fundamental attributes of systems, particularly the existing governance systems and norms that perpetuate inequalities' (ibid., ix). Governance systems are the kinds of phenomena that archaeology is able to detect.

There is no reason why such ideas and approaches could not be explored in archaeology and some have already begun to do so (see e.g. Leroy 2006; De Keyzer 2016; Cooper and Sheets 2012). Archaeology might benefit from giving systematic, creative thought to the question of how particular societal forms (kinds of 'governance systems') might fare in the face of climate and environmental change. There exist opportunities here to review known prehistoric cases from a comparative perspective and perhaps to arrive at generalizable, testable and revisable insights as to how different social formations might, on the one hand, produce vulnerability and, on the other, be able to deal with hazards.

However, the worry is that such a framing of the human-environment relation as producing vulnerability does not come to us naturally. As noted earlier, the human-environmental relationship is typically conceived using the thresholds model and our studies typically focus on detecting parallel shifts in environmental and archaeological proxies. In such a model, human action is likely to appear automatically as a response to external shifts (adaptation). By contrast, we would like to raise the possibility of conceiving human action as co-constitutive of the development of the human-environment relation.

There are (at least) two ways of attributing agency to humans in the face of external environmental change. One is to see humans as exercising agency in their coping in the aftermath of climate and/or environmental change. Here we afford humans agency, but that agency is exercised in response to an external event. The second way is to see the human-environment relationship as always already sociocultural in the way humans are positioned with respect to their environmental thresholds. The difference lies in the moment in time human agency enters the picture. There appears to be a tendency in the literature to focus upon the first kind of agency that views coping as a response to an external change. It is important to repeat, the very form of the palaeo-environmental research design, as focused on detecting parallels in changing environmental and archaeological proxies, automatically places that temporal focus on human coping, adaptation and response. The latter conception, which views human sociocultural organization as constitutive of the relationship from the beginning, seems underdeveloped in archaeology and, importantly again, the parallelistic form of research design implicitly and automatically militates against such a view.

A brief recourse to the case of modern Haiti in the wake of the 2010 earthquake is illustrative of the research design differences between the anthropology-of-hazards literature on the one hand, and palaeo-environmental archaeology on the other. In his account of the Haitian case, Anthony Oliver-Smith argued that the analysis of multiple catastrophic environmental impacts witnessed in the region across decades and centuries 'reveals how deeply embedded they were in the historical processes that resulted in the unequal distribution of risk and vulnerability at the national, regional, and local levels in Latin America and the Caribbean'. In this sense, Oliver-Smith (2012) wrote, in 2010 Haiti in some respects experienced the culmination of its own more than 500 -year earthquake'. What then follows in Oliver-Smith's account is a long history of colonialism and capitalism leaving its mark on Haiti and socially producing a grave state of vulnerability:

A lack of building codes, together with informal settlements, widespread undernourishment and hunger, disease, poor access to clean water or electricity, inadequate educational and health facilities and services at the national and municipal levels, and crime and corruption led to the construction of extreme vulnerability. In addition, Haitians were largely unaware of the seismic risk on the island, although seismologists had been warning of the possibility of a strong earthquake. 
If we take anthropology of hazards as our model, a striking characteristic is that the analysis is focused on the character of the social system prior to the external event which forms a basis for how that system channels the challenges and opportunities posed by the event. By contrast, archaeology typically takes primary interest in the social system after it has been impacted by the external event to see how the system has changed as a result of the event. The contrast here is real paradigmatic even - and the different paradigms give rise to different narratives of the past: one is focused on human innovation under pressure from external events, while the other is more political and focused on how certain societal dynamics might be producing vulnerability here and now, prior to the external event. In so far as palaeoclimatology and archaeology offer models beyond archaeology in how to think about the human-environment relationship, the scientists bear some political responsibility for where they see the crux of the matter, whether in posterior adaptation to external events or in the prior social production of vulnerability.

\section{Conclusion}

The above discussion has sought to understand the character of the debate around environmental determinism in archaeology. We reached three main conclusions:

- Palaeo-environmental studies in archaeology typically look for parallel shifts in the archaeological as compared to environmental and climate data.

- The biologistic idea of the environment as setting the thresholds within which humans exist underlies the view that changes in the thresholds are seen to necessitate a human response. There is an uncertainty as to how we should feel about biologism and the concept of thresholds (as plausible as they might be) and whether human beings should be viewed as merely responding to such external changes. Furthermore, reccurring cases from the literature suggest that the effects of the thresholds tend to be assumed rather than approached as an empirical question, which critics subsequently have indeed pointed out.

- Drawing inspiration from anthropology of hazards, archaeology might do well to think systematically about the social basis of hazards; that is, how societies might socially produce vulnerability in all of that society or in selected parts of it. Such social production would involve, for example, decision-making systems that are unable or unwilling to effectively coordinate - or, conversely, particularly well suited to coordinating - joint action to deal with changing conditions. It would also be desirable to broaden the temporal scope during which the phenomena of interest are considered to take place to include also the period of the social construction of vulnerability during which the institutions and other social dynamics of social vulnerability were shaped, and which precedes the putative environmental or climate event.

Our conclusions highlight the role and importance - indispensability, even - of interdisciplinary research into human-environment interactions. It is clear that specialists from a wide range of disciplines will be needed to answer questions about the thresholds on the one hand, and about the social production of vulnerability on the other, each of which concerns transformations that occur in a variety of very different scales and dimensions. Prehistoric research is uniquely placed to look at longer timelines and can view past environmental and cultural developments from a long-term perspective. The interaction of disciplines and the development of mutual, cultural and environmental explanatory models - while certainly more easily said than done - can help to avoid monocausal and unilinear determinism.

Acknowledgements. This research was funded by the Deutsche Forschungsgemeinschaft (DFG, German Research Foundation, Projektnummer 2901391021, SFB 1266). 


\title{
Beyond determinism. A case for complex explanations and human scale in framing archaeological causal explanations
}

\author{
Alexandra Ion \\ Francisc I. Rainer Institute of Anthropology, Bucharest, Romania, and McDonald Institute for Archaeological Research, \\ Cambridge University, UK \\ Email: ai300@cam.ac.uk
}

In a recent intervention, Romanian philosopher and essayist Andrei Pleşu (2018) writes on the topic of destiny,

We are not caught blindly in a network of 'fatal' causes and effects, rather we are integrated in an 'epic' structure, on a pathway which includes an 'intrigue', a host of significant events, sometimes stimulating, while at other times destabilising, in a 'story' whose makeup can only be revealed at the end of the 'spectacle'.

Archaeology is a discipline in the privileged position of engaging with things when they have seen their end lives and conclusions, at the end of the 'spectacle'. The downside is that sometimes too much time has passed, and traces have got lost, while at other times we forget that any story had a development, alongside moments when things could have turned out quite differently. Thus, upon trying to interpret change in the past, we sometimes end up with what Arponen and colleagues tackle in their article, namely deterministic explanations. Their article raises some points directly related to the implications of a particular kind of data set - palaeo-environmental studies - for framing historical explanations. This range of studies has become more important in recent years, as part of a wider resurgence of scientific technologies applied to interpreting the past. This trend has been accompanied by important implications, revealing the problem of integrating data sets of different kinds, from natural sciences to social sciences towards explaining historical processes. As the authors highlight, most often the explanation proceeds by identifying patterns in different data sets, climate record and archaeology, which are then correlated, and if they match they are interpreted in a causal key. But is life that simple?

It is great to see an article critically discussing this important topic. Even though it is hard to discuss environmental projects in the abstract, as I am sure that they vary widely in design, in what follows my commentary will briefly elaborate on what I take as the two key points of the argument: (1) the peril of too-simple explanations in archaeology, and (2) the scale on which we want our questions to operate. I take the authors' ideas more as a starting point for reflection, because at times it is not clear what position they support in relation to the themes discussed, e.g.: 'Roberts et al. would presumably also accept biologism as a basic tenet of scientific thinking ... yet the precise way the thresholds impinge upon human life is still up for debate' (p. 5) (but we never hear if the authors agree with them or not). Similarly, 'We bring up this branch of anthropology here not because we ourselves are champions of that perspective, but in order to provide a clearly contrasting picture of how to conceive the human-environment relationship' (p. 7) leaves the reader wondering about what the authors actually support and suggest.

First, the main argument of the paper revolves around the issue of whether palaeoenvironmental research is inherently deterministic or not: 'We write as an interdisciplinary team of researchers working in a joint research project, and we are interested in gaining 
clarity about what it might mean, if anything at all, to be a determinist' (p. 3). As a case study, the authors look at how palaeo-environmental research is designed, being 'typically oriented to detecting certain parallels between societal and environmental changes' (p. 3). While I agree with the authors in their diagnosis, I think the path they take to peel off the layers of the problem traps them in a yes-no game; that is, are environmental studies deterministic or not? How do they get here? From the start they frame the discussion within the two-cultures divide, and then they go through the processualism-postprocessualism debate, situating it within a distinction between conclusions of different kinds, i.e. comparative versus exploratory. Coupled with the topic of thresholds - 'the gist of the determinism debate ... exists precisely where, along the continuum from external influence to internal societal dynamics, to locate the moving forces of prehistoric transformations' (p. 4) - this leads to an inevitable conclusion that it is up to the empirical data to evaluate whether in every particular instance the palaeo-environmental causal explanation is enough, or if it is deterministic: 'At its heart, the question of determinism thus remains an empirical question, not an a priori charge levelled against a particular study' (p. 5). However, I feel that this is not the most helpful path to take when framing or evaluating our investigations, because it says nothing about how an ideal project should work. At the same time, 'empirical' is a concept which is not really attainable: e.g. we know when the Soviet Union fell; many have witnessed it; we have economic, geographic, political data; and yet there is still disagreement among specialists about what best explains this historical moment.

So the issue does not lie with the quality of evidence alone, although this matters, of course, and neither with whether climate or environmental data are intrinsically deterministic, but instead the problem is when we deal with too-simplistic hypotheses. In other words, the problem is when disciplines meet, and a data set is brought in to shed light on another data set; when palaeo-environmental data (or any other data set) provides a reductionist account (see also Hulme 2011 for an interesting overview of climate reductionism). Philosopher of science Adrian Currie (2018) writes about what he calls 'one-shot hypotheses': 'Such explanations identify a particular trigger for an event and then attempt to explain as much of the phenomena at hand as possible in light of that trigger'. Therefore, the problem is when complex biological, environmental and cultural interactions are reduced to one-shot hypotheses. Underlying this phenomenon which reduces complexities to simple $A \rightarrow B$ causal explanations are several elements, but one of the important ones is a power imbalance in the academic arena, a crisis of authority of the humanities. To this Mike Hulme $(2011$, 245) refers as 'a hegemony exercised by the predictive natural sciences over contingent, imaginative, and humanistic accounts of social life and visions of the future'.

Hence, maybe a more productive way forward is not to focus on which is the better explanation environmental or social - and instead to design more complex interpretive models, which allow for multiple factors to be integrated. At the same time, especially for the prehistoric past, we need more data points and precise dating techniques that would allow for refined connections.

The second point raised by Arponen and colleagues regards the value of anthropological insights in framing human-environment relations, and here as well their position is also sometimes vague ('We bring up this branch of anthropology here not because we ourselves are champions of that perspective' (p. 7)). Of course, this is a necessary component in understanding any past social phenomenon. In this way we start fleshing out explanations which are actually more plausible, as they include human agency and power relations: who created the environmental crisis? Were humans responsible to any degree? Are certain groups more likely to be affected? And so on. From the examples given in the paper, from Mayan droughts or UN Climate Change Resilience reports, to research into preindustrial activities and their climate impact (see an interesting piece in The conversation by Karl-Heinz Wyrwoll (2012) on 'How Aboriginal burning changed Australia's climate'), what appears as a simple 'natural' phenomenon is quickly shown to be the result of complex nature-culture interactions. 
This is not only a matter of 'common sense', but also a matter of explicitly recognizing that taking into account human agency is necessary if we are to reach any kind of historical understanding. As Artur Ribeiro $(2018,116)$ writes on the margins of the example of Dust Bowl farmers' migration to California in 1942, simple law-like explanations like Carl Hempel's 'people will tend to migrate to regions which offer better living conditions' is not just too general, but also doesn't really explain who migrates, and why to California. That is because human responses are always also cultural responses and understanding requires taking into account human intentionality. Consequently, the question which springs immediately to mind is: shouldn't we then change the viewpoint, and the scale, of our questions from the large-scale processes to human scales? The point of view which takes into account intentionality is one operating at a human scale, of bottom-up, refined case studies, whereas climate data tend to operate on large spatial-temporal scales. This is not a matter of opposing big-data narratives to small-scale case studies, but of grounding general environmental phenomena in the local human responses as a way past reductionist frameworks.

Thus, in response to the paper by Arponen et al., interdisciplinary archaeology projects require us to follow a two-step process: (1) more refined methodologies, with more data points, and complex interpretive frameworks instead of 'one-shot' explanations, and (2) a shift in points of view, by bringing environmental data into anthropological frameworks. In this way we might avoid a fatalist perspective (i.e. droughts came, civilizations collapsed, the end), and instead we recover something of that 'epic' structure of past destinies that Andrei Pleşu was referring to.

Archaeological Dialogues (2019), 26, 12-14

doi: $10.1017 /$ S 1380203819000060

\title{
Who is deterministic? On the nature of interdisciplinary research in archaeology
}

\author{
Kristian Kristiansen \\ University of Gothenburg, Sweden \\ Email: kristian.kristiansen@archaeology.gu.se
}

Arponen et al.'s paper is a timely discussion paper which raises basic issues about the relationship between environmental science and archaeology, and thus about the relationship between science and archaeology more broadly. My comments will therefore begin with a discussion of the nature of interdisciplinary research, as a background for re-evaluating the question of determinism in environmental research. Thus more recently we have seen a critical concern or even anxiety emerge over how to reconcile science-based and humanistic traditions of interpretation in a period of expanding importance of science-based knowledge in aDNA studies (Callaway 2018; Sørensen 2017; Kristiansen 2017). It raises the question of their relationship and of what provides good practice.

\section{Archaeology and science: what relationship?}

The relationship between archaeology and science has a long history, which allows us to extract certain historical regularities (Kristiansen 2014). The introduction of new science-based applications in archaeology is typically a two-phase process characterized by a 'break-through' phase of innovative basic research, which after 10 to 15 years is followed by a 'consolidation phase' of more widespread application (Martinon-Torres 2018, Figure 12.1). Between the two we sometimes find an intermediate phase of critical discussion and methodological refinements (Figure 1). 


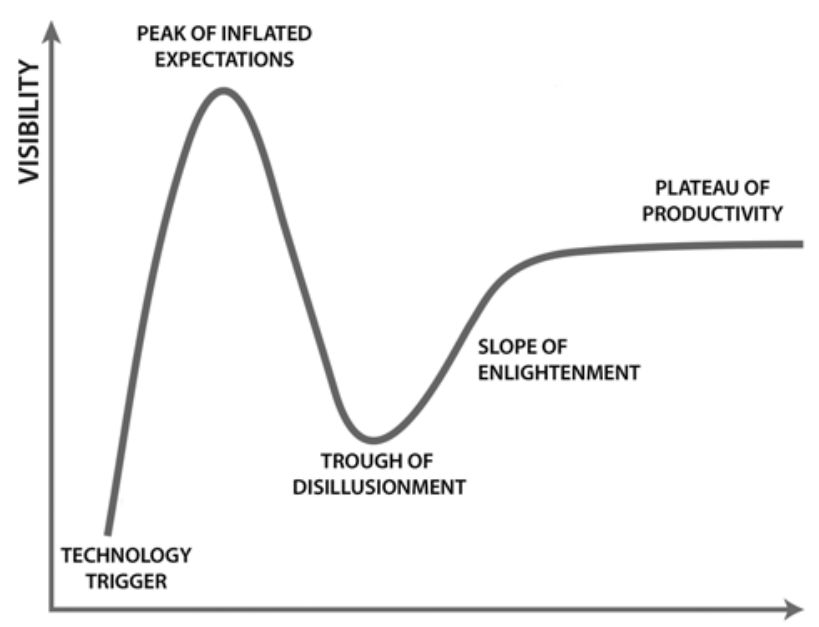

TIME
Figure 1. The so-called Gartner hype curve, here used to exemplify the process of new science innovations in archaeology (after Martinon-Torres 2018, Figure 12.1).

Breakthrough phase Groundbreaking basic research in a few leading research centres, publications in top-ranking science journals, redefinition of archaeological knowledge. Extensive research funding. Archaeological debates and theoretical reformulations to accommodate the new evidence. This is often followed by a phase of critique and re-evaluation, as in the case of the C14 calibration curve, which was then followed by a consolidation phase (or consensus phase) of more widespread application, lowering of prices, publication in more traditional archaeological journals in tandem with rapid accumulation of evidence that allows archaeological refinement of interpretations.

Right now strontium isotopic research is working hard to define more precise baselines, and what constitute proper baselines, being on its way into the consolidation phase (Frei and Frei 2011). Ancient DNA research is still peaking in the first breakthrough phase, but we witness mounting critique not of its methodologies, but rather of the historical and theoretical implications of the results (Sørensen 2017; Kristiansen 2017). Archaeometallurgy is yet another example of an early breakthrough of chemical analyses, critique and a rather long decline, followed by new methods, such as lead isotopes, and new relevance (Martinon-Torres 2018).

\section{Philosophy versus practice}

The philosophical position outlined in the Arponen et al. paper, that natural sciences adhere to a specific law-bound system of causal explanation, cannot be, and in practice rarely is, assigned to social and historical explanations. Most science-based disciplines are careful not to transcend their methodological limits of inference. This is where interdisciplinary dialogue enters the scene, as historical forces of social and economic institutions adhere to a different logic. It is here, in the dialectic between environmental and social forces, that explanations are to be formulated. Thus, while environmental research can define ecological thresholds, it is only through the interaction between society and environment that economic constraints can be defined, as they depend upon economic needs and social motivations. In my experience, environmental researchers, especially pollen botanists, are always careful not to seek historical explanations for environmental changes that go beyond what they observe in the record. Evidently, with the new European Reveals database of absolute pollen diagrams, and its capacity to reconstruct vegetational patterns across Europe, we are in a much better position to enter a constructive phase of interpreting large-scale economic or environmental changes, in opposition to the constraints of traditional single-pollen diagrams (Roberts et al. 2018). As stated in the Arponen et al.'s paper, truly integrated research 
teams can produce truly holistic explanatory models of past changes, but always based on probabilities, and always subject to new interpretations in the face of upcoming new evidence.

Thus it is indeed true that there is a giant step from establishing a correlation between variables to providing a causal explanation of these correlations. And in most of the cases I know of where attempts are made at taking this giant step it is done either by an interdisciplinary research team or by archaeologists working with such teams. Some recent examples may illuminate such good practice when an interdisciplinary team of researchers contributes to a common theme, such as megadrought (Weiss 2017), ecology and population dynamics (Harper et al. 2019), or the origin and circulation of metal (Radivojevic et al. 2018); or when a single researcher provides a synthesis based on solid interdisciplinary knowledge (Noble 2017; Chapman 2018; Müller 2016).

\title{
Who, then, is deterministic?
}

The answer is in the eye of the beholder. Scientists and archaeologists alike may hold to certain rules of basic environmental and human correlates within their respective fields, which some may call deterministic, but which are rarely applied to explain phenomena outside their area of relevance. Determinism arises only when attempts are made to apply explanations of data in one field to another field without due recognition of the methodological and interpretive practices of that discipline. And when you rely on monocausal explanations. It demands interdisciplinary research teams to account for multicausal historical or environmental transformations, and the application of a methodological and interpretive mix of quantitative and qualitative probabilities, whose outcome is therefore never deterministic, but whose success depends on an interdisciplinary familiarity of the team with both the data and the methods of each participating discipline. Given this definition, Arponen et al.'s paper seems to construct a problem that I find difficult to recognize in real academic practice, with minor exceptions of researchers who do not respect the limits of their knowledge. Most of their examples are indeed based on probabilistic interpretations, but where researchers place different weight on the dominant forces of change.

Interdisciplinary research thus demands that its practitioners embrace and understand the other contributing disciplines, which is mostly honoured. More often than not it is archaeologists who venture into attempts at synthesizing interpretations of complex science-based and archaeological evidence, which is fine as long as they are based on a proper knowledge of the disciplinary fields involved. And that goes also for scientists entering the explanatory field of archaeology. It is hard work but most contributions in the field are sound attempts at interdisciplinary probabilistic interpretation, and not deterministic in my definition.

\section{From determinism to accountability. Archaeology, anthropology and ethics}

\author{
Kathryn Lafrenz Samuels \\ Department of Anthropology, University of Maryland, USA \\ Email: lafrenzs@umd.edu
}

The discussion by Arponen et al. inserts itself into long-standing debates about the place of causality and determinism in archaeological interpretation. While some of the discussion might feel like retreading familiar ground in those debates, the authors bring a refreshing clarity of exposition to the problem, and more importantly they propose several promising directions for future 
research. For example, their exhortation to 'see the human-environment relationship as always already sociocultural' (p. 8) should be firmly established by now, but I agree with their assertion that this perspective 'seems underdeveloped in archaeology' (p. 8) and that looking to anthropology is one especially productive route for developing such a sensibility. In the following I wish to extend and respond to their arguments by (1) addressing how anthropological approaches might best be incorporated into archaeological research on palaeo-environments and coupled humanenvironment systems, and (2) highlighting the ethical and moral dimensions of this process as integral to it.

Certainly, calls for integrating anthropology into interdisciplinary work on human-environment interactions entrain methodological concerns, but they also elicit ethical concerns as well. Indeed, reading between the lines, I found the ethical and moral dimensions of archaeological research to be implicit in much of the authors' argument. Sometimes these dimensions are overtly stated too, for example when the authors note that the temporal scope of archaeological research design prompts questions of responsibility, insofar as archaeology is offering something 'beyond archaeology' for thinking about the human-environment relationship. As such, the authors note, 'the scientists bear some political responsibility for where they see the crux of the matter, whether in posterior adaptation to external events or in the prior social production of vulnerability' (p. 9).

However, the ethical implications in the text reach much farther: the authors' focus on research design foregrounds how and why archaeologists decide which research is worth doing to begin with, which questions are worth asking, and which answers suffice. This returns us to what archaeology is offering to the realm 'beyond archaeology', to interdisciplinary knowledge production and policy making, and to society more broadly. What is entailed in that socio-moral space 'beyond archaeology', and how do we choose to engage with it? How will it shape the ethics of archaeological research? These are big questions, of course, but they are becoming increasingly urgent in a world grappling with anthropogenic climate change.

In perhaps one of their most perceptive and important statements, the authors note that 'an exploration of the core of the determinism debate will turn out to concern at least as much the selfreferential foundations of our own scientific conduct as the causal foundations of prehistoric transformations' (p. 2). Is this not always the case - and yet how rarely is it examined? The authors' suggestion to incorporate anthropological knowledge offers an even more visible and clear-cut means for taking stock of how archaeological research itself (and scientific research more broadly) is 'always already sociocultural'. In highlighting these facts and conditions of archaeological research we can better fit archaeological knowledge to the present needs of society.

Arponen et al. make several suggestions about how to use anthropological insights, specifically on the social basis of hazards and the social production of vulnerability. They propose focusing on governance systems, from decision making, resilience and institutional flexibility for adaptation, to marginalization and social exclusion. Approaches focusing on resilience and adaptation are not without their own issues, for example in preferencing status quo relations. However, analysing governance systems and social marginalization is very useful for moving debates beyond determinism and unidirectional causal pathways to instead think more broadly in terms of complex webs and systems of relationships. My primary concern is the ways in which the authors suggest applying anthropological insights to the archaeological past, which include returning to comparative, typological, generalizable, even 'testable' approaches. I would like to suggest that there are more productive, or at least anthropological, ways to go about this, under a theory of science attuned to accountability.

Compared to other social sciences, anthropology is particularly suited to studying systems of relationships, or what have been called 'non-statistical social facts' (Malkki 2007, 167, citing Leach 1967, 76-77). Anthropology is invested in producing 'situated knowledge', a scientific approach 
that embraces the limited and fractured perspectives espoused in Donna Haraway's (1988) feminist theory of science. Anthropologists typically prefer to generalize within individual cases, rather than between. They are interested in holistic accounts of the dense networks of relationships that form a specific context. Studying vulnerability, social marginalization and governance systems will quickly disabuse any researcher from speaking about 'human' (i.e. species-level) interactions with the environment, as they are sensitive to the significant heterogeneity within individual societies and the diversity between different cultures. Following the authors' suggestion to create typologies of governance systems for comparative purposes might give some sort of answers, but it flattens our understanding of what is going on in the past, and - let us be clear - the answers will say more about ourselves, as the practice of such peg fitting and 'butterfly collecting' (Leach 1961) privileges a priori assumptions in the research design.

Anthropologists have learned to embrace the fact that all research design begins from the researcher, whose individual personhood and social lenses can never be extracted from the process of knowledge production. This recognition is a key component of 'situated knowledge'. In this respect, too, research is understood as a dialogue between the observer and the observed, expanding the universe of conversability (Geertz 1973), and providing a 'moral science of possibilities' (Carrithers 2005). So archaeological research should be understood as a dialogue between past and present, especially when employing anthropological methods. It is simply impossible to be a oneway street, simply or only applying anthropological insights to the past, but requires full attention to how archaeological knowledge also contributes and is bound up within the present, being 'always already sociocultural'.

Importantly, 'situated knowledges' build from a theory of science that, in the pursuit of more powerful forms of objectivity, seeks accountability more than predictability. In other words, situated knowledges produce accountable objectivity, and as such offer better accounts of the world. Haraway's theory of science calls for 'accountable scientific visions' which are 'scientific accounts more aware of the social world in which they arise and which they in turn participate in forming' (Stephens 1994, 71).

How different would environmental archaeology look if talk about determinism and causality were retired and instead research was designed around questions of accountability? Asking this question raises several others. How well is the causality paradigm serving archaeology? Maybe quite well, because it offers relatively 'easier' or apparently straightforward answers. But how well is the causality paradigm serving the usefulness of archaeological knowledge for society? In this case the answer may be not very well, and in fact even serving dangerously.

Incorporating a paradigm of accountability proceeds on two fronts. First, with respect to knowledge about the past, governance systems and social marginalization are areas of research that lend themselves well to reframing archaeological interpretations around accountability, around the complex webs of relationships, alliances, embodiments and exclusions that might compose an archaeological analysis of accountability. Viewing social and political analysis through the lens of accountability long precedes Haraway, at least for anthropological theories of society. For example, the historically informed work of E.E. Evans-Pritchard analysed political systems according to a rubric of accountability, identifying internal arbitration as the internal 'glue' of accountability that held societies together, and defining societies externally by where accountability broke down.

Second, pursuing 'situated knowledge' about socio-environmental relations in the past will, as discussed above, necessarily involve accountability to the social needs of the present, and accountability for how archaeological knowledge is produced and used. These needs are set within a moral universe shaped by the socio-environmental challenges of our time. Focusing on how anthropological approaches might best be brought to bear on archaeological research on palaeo-environments and coupled human-environment systems has highlighted the ethical and moral dimensions of this work, especially under the shadow of anthropogenic climate change. The authors note that the determinism debates are 
fuelled by a particular uncertainty about the idea of biologism and thresholds: on the one hand, the biologistic idea of the climate and environmental thresholds being fundamental to human existence is eminently plausible, yet, on the other hand, many also feel that the picture overtly and unduly externalizes the drivers of change in human societies (p. 4).

With the clarity of future hindsight, how else might we understand the determinism debates today but as some scientistic ouroboros of climate anxiety, of an archaeological discipline coming to terms with the anthropogenic nature of present climate change and how the discipline might address it?

Overall, climate change research across the disciplines is increasingly understanding anthropogenic climate change as, at base, a fundamentally moral issue (Broome 2012; Gardiner 2011). Archaeological research can contribute to explicating these moral foundations through research on accountability and governance in the past, and how historical cases might illuminate accountability and governance issues in the present. At the same time, archaeology can contribute by making explicit the accountability of archaeology to society, including how archaeology itself contributes to the drivers of climate change, and is implicated within the social production of vulnerability and social exclusion that will exacerbate the impacts of climate change for many.

Archaeological Dialogues (2019), 26, 17-19

doi:10.1017/S1380203819000072

\section{Environmental determinism and archaeology. Red flag, red herring}

Felix Riede

Aarhus University, Denmark

Email: f.riede@cas.au.dk

When first asked to comment upon the contribution of Arponen et al. on environmental determinism in archaeology - a red flag to many - I became excited that the topic is receiving attention again and, not least, that this attention is translating into printed debate. I commend the authors on their effort, also for bringing together multiple voices in their article. All too rarely do theoretical contributions translate into multiple authorship. I cannot in any way disagree with their key conclusions, namely that investigations of deep-time relations between humans and the environment are not just timely but important, and that archaeology should make full use of its rich array of data, cases and dissemination possibilities to investigate them and make them relevant in the present.

That said, it is worth, I believe, adding some commentary to the way in which Arponen et al. frame their discussion, to how they gloss over critical issues of analytical scale and purpose, and to the solution they offer. Arponen et al. acknowledge that the tired paradigmatic straw men of processual and postprocessual archaeology may no longer be of much use, but they nonetheless swiftly link processualism with environmentally deterministic positions. In referencing Arkush (2011), they pitch studies of the postprocessual non-deterministic variety focusing on 'contingency' and 'agency' against those of the processual determinists focusing on 'process' and 'conditions' respectively. As much as this perceived contrast has been canonized in textbook versions of disciplinary history, it is fundamentally flawed and should be filed under 'of historical interest only'. Archaeology is a historical science whose epistemological undergirding, data 
and explanatory goals mirror most closely disciplines such as evolutionary biology and historical linguistics rather than, as many processualists fatally assumed, physics or chemistry. Critically, in the historical sciences, attention to contingency, to process, to agency and to conditions is everpresent - after all, without the interplay of these key factors there would simply be no history, be it cultural or organismal. Moreover, meaningful historical causation - that is, patterns and processes of culture change over time - are only ever inferred from correlations and are only ever probabilistic. The epistemic and data-structural likeness amongst the historical sciences was already stressed by philosophers of science such as Whewell (1847) and has recently been discussed again by Mesoudi, Whiten and Laland (2006) and Currie (2018b). Granted, the common institutional placement of archaeology within the humanities or social sciences has resulted in student recruitment, education and socialization trajectories as well as practices that perpetuate the opposition between the humanities and the natural sciences. It is these practices that continue to feed the spectre of C.P. Snow's (1959) antagonistic and aggressive 'two-cultures' argument also referred to by Arponen et al. - but it is my belief that we really must no longer pander to this out-dated way of viewing the sciences if indeed our concern is to explain, in a replicable and transparent manner, real-world phenomena that have come to us from an actual past.

Along with Arponen and colleagues, I do not reject the notion that archaeology is conducted in the present and responds to personal, social and political concerns. To the contrary, I am very much concerned with the ethical dilemmas posed precisely by conducting research on the causal connections between past environmental change and human responses (Riede, Andersen and Price 2016; Riede 2018). Archaeology is an accommodating discipline and there are many ways in which to generate new knowledge of the past and just as many ways to make this knowledge do good work in the present. As Arponen et al. rightly note, being cognizant of our discipline's role in the present does not automatically lead to a radical (and ultimately counterproductive) social-constructivist position (Shennan 2004). Furthermore, as our colleagues in history are increasingly pointing to the causal role of environmental change in cultural change over the last centuries, hard-line positions that decouple cultural, social and political histories from environmental histories ring increasingly hollow (Chakrabarty 2009). The growing sub-field of environmental history is showing us, thanks to the commonly much more dense availability of sources, just how intricately human individual and societal trajectories, political authority, warfare and migration all major analytical concerns also in archaeology - are intertwined with environmental changes and extreme events (e.g. Mauch and Pfister 2009; Behringer 2010; Parker 2014).

In suggesting a solution to the conundrum of determinism as perceived by Arponen and colleagues, they propose that archaeologists turn to the anthropology of disaster that argues for the social and historical construction of vulnerability and resilience. This literature is indeed inspiring - it has definitely inspired me (e.g. Riede 2017; 2014) - but it is also notoriously diverse, if not outright confusing (Otto et al. 2017; Lorenz 2013). Most available frameworks are difficult to align with historical analyses beyond description. No ready operationalizations are available, which is particularly problematic as Arponen and colleagues also claim that understanding human-environment interactions ultimately is an empirical matter. But better data will not bring salvation without robust theory and transparent methodologies. My counterproposal is therefore to look towards the powerful conceptual and methodological apparatus developed by quantitatively minded biologists who similarly struggle to understand the causal relations between the myriad environmental parameters and both past and current distributions of plants and animals, their complex interactions and their histories. The terminology of disaster-risk-reduction studies can be aligned with that of cultural evolution (cf. Brewer and Riede 2018), and human behavioural ecology offers a robust framework for how environmental cues shape key life-history decisions (Boone 2002). With these ecological envelopes in place, methods providing reasoned and replicable insights into precisely which factors influenced the presence/absence of particular human groups as identified by artefactual proxies can be developed (Franklin et al. 2015; Robinson and Riede 2018); an integration with quantitative cultural-historical (i.e. phylogenetic) approaches is also possible. At all times, 
the intended scale and object of explanation must be kept firmly in mind, however. Environmental changes only ever underdetermined the historically contingent changes occurring within any given past community; many features we encounter in the archaeological record - for instance, the specifics of projectile-point shape beyond ballistic requirements - cannot be explained meaningfully with regard to climate and the environment but rather are the product of contingency and cultural transmission processes. Yet, when it comes to the core concerns and explanatory strengths of prehistoric archaeology - palaeodemography, migration, political change and warfare - ignoring the environment most likely will lead to flawed explanations. If, then, we bring the epistemology of the historical sciences and transparent and replicable methods to bear on the question of prehistoric human-environment relations, determinism actually becomes a red herring.

Archaeological Dialogues (2019), 26, 19-24

doi: $10.1017 / \mathrm{S} 1380203819000102$

\title{
Two cultures in the times of interdisciplinary archaeology. A response to commentators
}

\author{
V. P. J. Arponen, ${ }^{1, \star}$ Walter Dörfler, ${ }^{2}$ Ingo Feeser, ${ }^{3}$ Sonja Grimm, ${ }^{4}$ Daniel Groß, ${ }^{5}$ Martin Hinz, ${ }^{6}$ \\ Daniel Knitter, ${ }^{7}$ Nils Müller-Scheeßel, ${ }^{8}$ Konrad Ott, ${ }^{9}$ and Artur Ribeiro ${ }^{10}$ \\ ${ }^{1}$ University of Kiel, SFB 1266, Leibnizstr. 3, 24118 Kiel, Germany, ${ }^{2}$ University of Kiel, Institute of Pre- and Protohistoric \\ Archaeology, Johanna-Mestorf-Str. 2-6, 24118 Kiel, Germany, ${ }^{3}$ University of Kiel, Institute of Pre- and Protohistoric \\ Archaeology, Johanna-Mestorf-Str. 2-6, 24118 Kiel, Germany, ${ }^{4}$ Center for Baltic and Scandinavian Archaeology, Stiftung \\ Schleswig-Holsteinische Landesmuseen Schloss Gottorf, 24837 Schleswig, Germany, ${ }^{5}$ Center for Baltic and Scandinavian \\ Archaeology, Stiftung Schleswig-Holsteinische Landesmuseen Schloss Gottorf, 24837 Schleswig, Germany, ${ }^{6}$ University of \\ Bern, Institut für Archäologische Wissenschaften, Prähistorische Archäologie (Ur- und Frühgeschichte) and Oeschger \\ Centre for Climate Change Research (OCCR), Mittelstrasse 43, 3012 Berne, Switzerland, ${ }^{7}$ University of Kiel, Department \\ of Geography, Physical Geography, Christian-Albrechts-Universität zu Kiel, Ludewig-Meyn-Str. 14, 24118 Kiel, Germany, \\ ${ }^{8}$ University of Kiel, Institute of Pre- and Protohistoric Archaeology, Johanna-Mestorf-Str. 2-6, 24118 Kiel, Germany, \\ ${ }^{9}$ University of Kiel, Department of Philosophy, Leibnizstr. 6, 24118 Kiel, Germany and ${ }^{10}$ University of Kiel, SFB 1266, \\ Leibnizstr. 3, 24118 Kiel, Germany \\ *Corresponding author. Email: varponen@gshdl.uni-kiel.de
}

We would like to begin by thanking the journal and the commentators for their time and attention.

For us, the comments to our paper illustrate a certain diversity pertaining to how the scientific field positions itself regarding environmental determinism and connected issues. A discussion of this diversity will lead us to revisit some of the key themes of our paper in the context of the comments.

For example, in the responses of Kristiansen and Riede, we see a bold embrace of something one might term archaeological science (Killick 2015). From that point of view, the idea of 'social and historical construction of vulnerability and resilience' is something that - while inspiring has '[n]o ready operationalizations' so far available in archaeology (Riede, p. 18). In a comment like this we see that, for Kristiansen and Riede, archaeology is fundamentally a data-driven science. Interpretive efforts stand or fall with how data and interpretations are coupled; that is, with how interpretive ideas are operationalized. The longer-standing critique that archaeological theory is dead unless theories make an explicit effort at operationalizing their key concepts (see e.g. Bintliff 2011; Kristiansen 2017; Johnson 2006) comes to mind. In any case, for Riede and Kristiansen, the dimension in which archaeological explanation and understanding can fundamentally improve appears to be the development of always sharper and sharper methods of data extraction and analysis. For them, all systems are already go and essentially just need more time to operate, iterate 
and refine themselves. Famously, in recent years, Kristiansen has been using the term 'third scientific revolution' to designate the new archaeological science (Kristiansen 2014).

It is worth observing here that in our original paper, we in fact sought to adopt a mediator position seeking to understand the contours of the debate about determinism, rather than go on branding this or that piece of research deterministic or not - given the heterogeneous makeup of the present author group, that was only natural. That may explain some of the charges of vagueness raised against us by a number of commentators. In either case, for the archaeological science our original paper wanted to offer the idea of implicating governance structures as a potential dimension in which the social production of vulnerability and resilience can be seen to operate. This would be a dimension that also archaeological science knows how to approach insofar as quantifiable (if indirect) data pertaining to social stratification - as evidenced in changing burial practices, architecture and the rest of the standard archaeological fare - are available.

A second effort contained in our original paper by way of bringing a social construction of vulnerability and a resilience perspective to archaeological science - which, however, does not seem to have attracted attention from the commentators - concerned the difference in the temporal scope of study taken regarding hazards and disasters. As argued in our original paper, where in archaeology our research designs tend to look for convergence of environmental/climate proxies and archaeological proxies with a decided temporal focus placed on the post-change moments in time, the literature on the social construction of vulnerability would place the temporal focus upon the longue durée before the disaster.

In any case, in Lafrenz Samuels's and Ion's comments, we see a more reserved attitude to archaeological science. Lafrenz Samuels, for example, picks up on the aforementioned idea of forms of governance as a possible pathway towards studying the social construction of vulnerability and resilience. She argues that such an approach merely threatens to revert us to bygone 'comparative, typological, generalizable, even "testable" approaches', while more modern, 'more productive, or at least anthropological', approaches are also available and, according to her, preferable (p. 15). In its place, a more anthropological approach sets off from the concepts of 'situated knowledges', a concept that Lafrenz Samuels briefly illustrates with reference to prominent work such as that by Donna Haraway as well as Clifford Geertz. From the point of view of archaeological science, following Riede and Kristiansen, a central challenge would certainly seem to be the operationalization of this type of concept in archaeology: how are such knowledge claims to be evaluated by reference to data? The present point is not to seek to answer that much-discussed question (Wylie 2002, Chapter 3), but to point out that in discussions like these, something like the processual/postprocessual contrast seems to be alive and well. We will return to this theme shortly below.

That said, we want to explicitly side with Lafrenz Samuels's call for sensitivity to accountability in the way a science forms its object of study - that, after all, was effectively the closing statement of the original paper as well. That is to say, there are (at least) two ways of framing the character of the human relationship with changing climate and environment. We may frame it apolitically as a technological challenge of humans developing and using technology and other innovations to cope with and maybe even take advantage of the changes; or we frame it politically by implicating different sociopolitical forms of organization of human social and cultural life as producing vulnerability and resilience respectively. These competing ways of framing the situation are very much with us in today's environmental discourse and we need to hold ourselves accountable for whichever framing we use, for example, in archaeology. Why? Because the way we frame the issue may in its own perhaps small way set an example of how others can begin to think about framing it.

We believe that most readers would side with political framing and accountability, arguing, however, that this ought not to mean a rejection of the point of view that the environment and climate set the threshold or envelope within which humans produce their material basis of existence, an envelope that human technological and innovative resourcefulness may also alter. 
This idea of a synthesizing, multidisciplinary approach again takes us to the argument made by some commentators that our original paper propounded the tired, old processual/postprocessual division in archaeology.

Thus Ion's comment casts deterministic explanations as one-shot, reductionist explanations to which multifactor views with 'more data points, and complex interpretive frameworks', are preferable (p. 12). On the face of it, Riede and Kristiansen would readily agree in that they too champion the (in their view already ongoing) interdisciplinary archaeological science enterprise.

There is more than meets the eye here, however. Recently elsewhere, Ion argued that in archaeology we are still some way from 'what a truly integrative narrative would look like' (Ion 2017, 179). A key issue identified by Ion is epistemological: a given phenomenon is defined in a particular way that implicitly structures research. Her example is how aDNA technology has seemingly allowed archaeology to capture the so-called Neolithic Revolution in a new, more perceptive way:

In trying to see if the Neolithic 'tool-kit' (dwellings, agriculture, pottery) was brought over by certain people, the 'Neolithic' man (may s/he be from the Starcevo-Cris, Dimini, or Gumelnita culture) is sampled for DNA, and then compared with other 'Neolithic' individuals from some other places/cultures (ibid., 187).

Ion points out that what is going on in a research design like this is the epistemological, semantic, equation of the distribution of aDNA with the concept of an expanding Neolithic Revolution. That is to say, where we have evidence of aDNA as it were travelling from place to place, there we find the Neolithic Revolution spreading out.

Now, arguably, Ion's argument is formally closely related to ours in the original paper. We argued that there is a popular form of research design that searches for parallel developments in environmental and climate proxies as compared to archaeological proxies. Where there are parallels, we have a reason to believe that the changing environment and climate are somehow influencing human development. As for Ion, there is an implicit epistemological definition at issue here in the manner in which a phenomenon of a certain order such as sociocultural change is conceptualized in relation to a phenomenon of another order, namely changing environment and climate or changing distribution of aDNA.

Again, similar to Ion, the denial of such an epistemological equation does not amount to saying that changes in the environment and climate - or in aDNA - are unrelated to sociocultural changes. As Ion puts it, 'I also think that scientific data brings an important contribution, given that humans are the result of contingent histories of genetic, biologic, environmental, and cultural interactions' (Ion 2017, 180).

In the original paper, we spoke of something called biologism as possibly accounting for why the changing environmental and climate envelope, in tandem with sociocultural changes, is taken to indicate the presence of a relationship of influence here. Biologism can be described as the view that, as biological beings, humans are subject to and dependent on the affordances of their environment in terms of the material basis of human existence. In such reasoning, there indeed is a prima facie connection between environment/climate and socioculture. We suspect something similar is going on in the equation of aDNA distribution with the advancing Neolithic Revolution: humans reproduce biologically, handing down both their biological and their sociocultural heritage to the next generation. Therefore, prima facie, a particular distribution of some markers of biological heritage is indeed an indication of the distribution of sociocultural heritage.

The problem Ion has with the equation of aDNA with a sociocultural phenomenon is that the equation limits our understanding of the sociocultural dimension - it limits 'the understanding of human beings to genetic entities', she argues (Ion 2017, 187). However, alongside key tenets such as biologism, scientific thought builds upon the idea that surface complexity can be comprehended by 'a representation of the system's critical components', as Coombes and Barber $(2005,305)$ put it in the passage quoted in our original paper. To put it provocatively, where Ion sees limited 
understanding and Lafrenz Samuels sees ignorance of 'situated knowledges', others might see a superior reduction to the essentials. This difference might describe the hard core of the debate about determinism and archaeological science.

To conclude, on the question whether our original paper perpetuates the 'two-cultures' distinction, from engagements in conferences and the like over the past several years, we can tell that there is a lot of goodwill around for a synthesizing position in archaeology. At the same time, exchanges such as our original paper has given rise to here might be taken to demonstrate that some fundamental differences in research orientation remain.

\section{References}

Arkush, E., 2011: The year in review. Explaining the past 2010, American anthropologist 113(2), 200-12.

Behringer, W., 2010: A cultural history of climate, Cambridge.

Bettinger, R.L., R. Garvey and S. Tushingham, 2015: Hunter-gatherers. Archaeological and evolutionary theory, 2nd edn, New York (Interdisciplinary Contributions to Archaeology).

Bhaskar, R., 2008: A realist theory of science, London.

Bicho, N., and J. Cascalheira, 2018: Global perspectives on the impact of drastic environmental changes in hunter-gatherer technologies, Journal of Quaternary science 33(3), 255-367.

Binford, M.W., A.L. Kolata, M. Brenner, J.W. Janusek, M.T. Seddon, M. Abbott and J.H. Curtis, 1997: Climate variation and the rise and fall of an Andean civilization, Quaternary research 47(2), 235-48.

Bintliff, J., 2011: The death of archaeological theory?, in J. Bintliff and M. Pearce (eds), The death of archaeological theory?, Oxford, 7-22.

Boone, J.L., 2002: Subsistence strategies and early human population history. An evolutionary ecological perspective, World archaeology 34, 6-25.

Brewer, J., and F. Riede, 2018: Cultural heritage and climate adaptation. A cultural evolutionary perspective for the Anthropocene, World archaeology, 1-16.

Broome, J., 2012: Climate matters. Ethics in a warming world, New York.

Callaway, E., 2018: The battle for common ground, Nature 555, Feature News.

Carrithers, M., 2005: Anthropology as a moral science of possibilities, Current anthropology 46, 433-56.

Chakrabarty, D., 2009: The climate of history. Four theses, Critical inquiry 35, 197-222.

Chapman, J., 2018: Climatic and human impact on the environment? A question of scale, Quarternary international 496, 3-13.

Clarke, D.L., 1972: Models and paradigms in contemporary archaeology, in D.L. Clarke (ed.), Models in archaeology, London, $1-60$.

Contreras, D.A., 2016: Correlation is not enough, in D.A. Contreras (ed.), The archaeology of human-environment interactions. Strategies for investigating anthropogenic landscapes, dynamic environments, and climate change in the human past, London, 3-22.

Coombes, P., and K. Barber, 2005: Environmental determinism in Holocene research. Causality or coincidence? Area 37(3), 303-11.

Cooper, J., and P.D. Sheets, 2012: Surviving sudden environmental change, Boulder, CO.

Currie, A., 2018: Consensus schmosensus. Dead dinosaurs, big rocks \& simple stories (1 May 2018), at www.extinctblog.org/ extinct/2018/5/1/consensus-schmosensus-dead-dinosaurs-big-rocks-simple-stories, accessed 8 January 2019.

Currie, A., 2018b: Rock, bone, and ruin. An optimist's guide to the historical sciences, Cambridge, MA.

De Keyzer, M., 2016: All we are is dust in the wind. The social causes of a 'subculture of coping' in the late medieval covers and belt, Journal for the history of environment and society, 1, 1-35.

Dilthey, W., 2008 (1883): Introduction to the human sciences. An attempt to lay a foundation for the study of society and history, Detroit.

Dobres, M.A., and J. Robb (eds), 2000: Agency in archaeology, London.

Elder-Vass, D., 2010: The causal power of social structures. Emergence, structure and agency, Cambridge.

Erickson, C.L., 1999: Neo-environmental determinism and agrarian 'collapse' in Andean prehistory, Antiquity 73(281), 634-42.

Faulseit, R.K. (ed.), 2015: Beyond collapse. Archaeological perspectives on resilience, revitalization, and transformation in complex societies, Carbondale, IL.

Franklin, J., A.J. Potts, E.C. Fisher, R.M. Cowling and C.W. Marean, 2015: Paleodistribution modeling in archaeology and paleoanthropology, Quaternary science reviews 110, 1-14.

Frei, K.M., and R. Frei, 2011: The geographic distribution of strontium isotopes in Danish surface waters. A base for provenance studies in archaeology, hydrology and agriculture, Applied geochemistry 26, 326-40.

Gardiner, S.M., 2011: A perfect moral storm. The ethical tragedy of climate change, Oxford.

Geertz, C., 1973: The interpretation of cultures, New York. 
Grattan, J., 2006: Aspects of Armageddon. An exploration of the role of volcanic eruptions in human history and civilization, Quaternary international 151(1), 10-18.

Haraway, D., 1988: Situated knowledges. The science question in feminism and the privilege of partial perspective, Feminist studies 14, 575-99.

Harper, T.K., A. Diachenko, Y.Y. Rassamakin and D.J. Kennett, 2019: Ecological dimensions of population dynamics and subsistence in Neo-Eneolithic Eastern Europe, Journal of anthropological archaeology 53, 92-101.

Hodder, I., 1985: Postprocessual archaeology, Advances in archaeological method and theory 8, 1-26.

Hodder, I., and S. Hutson, 2003: Reading the past. Current approaches to interpretation in archaeology, 3rd edn, Cambridge.

Hoggarth, J.A., M. Restall, J.W. Wood and D.J. Kennett, 2017: Drought and its demographic effects in the Maya lowlands, Current anthropology 58(1), 82-113.

Hoggarth, J.A., S.F.M. Breitenbach, B.J. Culleton, C.E. Ebert, M.A. Masson and D.J. Kennett, 2016: The political collapse of Chichén Itzá in climatic and cultural context, Global and planetary change 138, 25-42.

Hulme, M., 2011: Reducing the future to climate. A story of climate determinism and reductionism, Osiris 26(1), 245-66.

Ion, A., 2017: How interdisciplinary is interdisciplinary? Revisiting the impact of aDNA research for the archaeology of human remains, Current Swedish archaeology 25, 177-98.

Johnson, M.H., 2006: On the nature of theoretical archaeology and archaeological theory. Archaeological dialogues 13(2), 117-32.

Jones, T.L., G.M. Brown, L.M. Raab, J.L. McVickar, W.G. Spaulding, D.J. Kennett, A. York and P.L. Walker, 1999: Environmental imperatives reconsidered. Demographic crises in western North America during the medieval climatic anomaly, Current anthropology 40(2), 137-70.

Killick, D., 2015: The awkward adolescence of archaeological science, Journal of archaeological science 56, 242-47.

Kintigh, K.W., J.H. Altschul, M.C. Beaudry, R.D. Drennan, A.P. Kinzig, T.A. Kohler, W.F. Limp, H.D.G. Maschner, W.K. Michener, T.R. Pauketat, P. Peregrine and J.A. Sabloff, 2014: Grand challenges for archaeology, American antiquity 79(1), 5-24.

Kolata, A.L. (ed.), 1993: The Tiwanaku, Oxford.

Kristiansen, K., 2014: Towards a new paradigm? The third science revolution and its possible consequences in archaeology, Current Swedish archaeology 22, 11-34.

Kristiansen, K., 2017: From deconstruction to interpretation. Archaeological dialogues 24(1), 41-44.

Kristiansen, K., 2017: The nature of archaeological knowledge and its ontological turns, Norwegian archaeological review, at http://dx.doi.org/10.1080/00293652.2017.1372802.

Kuhn, T.S., 1996: The structure of scientific revolutions, 3rd edn, Chicago.

Leach, E., 1961: Rethinking anthropology, New York.

Leach, E., 1967: An anthropologist's reflection on a social survey, in G. Jongmans and P.C.W. Gutkind (eds), Anthropologists in the field, Assen, 75-88.

Leroy, S.A.G., 2006: From natural hazard to environmental catastrophe. Past and present, Quaternary international 158(1), $4-12$.

Lohse, S., 2017: Pragmatism, ontology, and philosophy of the social sciences in practice, Philosophy of the social sciences 47(1), $3-27$.

Lorenz, D.F., 2013: The diversity of resilience. Contributions from a social science perspective, Natural hazards 67, 7-24.

Lucas, G., 2017: The paradigm concept in archaeology, World archaeology 49(2), 260-70.

Malkki, L.H., 2007: Tradition and improvisation in ethnographic field research, in A. Cerwonka and L.H. Malkki (eds), Improvising theory. Process and temporality in ethnographic fieldwork, Chicago, 162-88.

Martinon-Torres, M., 2018: Mobility, minds and metal. The end of archaeological science?, in X.-L. Armada, M. MourilloBarosso and M. Charlton (eds), Metal, minds and mobility. Integrating scientific data with archaeological theory, Oxford, 161-69.

Mauch, C., and C. Pfister (eds), 2009: Natural disasters, cultural responses. Case studies toward a global environmental history, Lanham, MD.

Meggers, B.J., 1954: Environmental limitations on the development of culture, American anthropologist 56, 801-24.

Meggers, B.J., 2001: The continuing quest for El Dorado. Round two, Latin American antiquity 12, $304-25$.

Mesoudi, A., A. Whiten and K.N. Laland, 2006: Towards a unified science of cultural evolution, Behavioural and brain sciences 29, 329-83.

Middleton, G., 2017: Understanding collapse. Ancient history and modern myths, Cambridge.

Müller, J., 2016: From the Neolithic to the Iron Age. Demography and social agglomeration: the development of centralized control?, in D.K.M. Fernandez-Götz (ed.), Individualization, urbanization and social differentiation. Eurasia at the dawn of history, Cambridge, 106-24.

Noble, G., 2017: Woodland in the Neolithic of Northern Europe. The forest as ancestor, Cambridge.

Oliver-Smith, A., 1996: Anthropological research on hazards and disasters, Annual review of anthropology 25, 303-28.

Oliver-Smith, A., 2012: Haiti's 500-year earthquake, in M. Schuller and P. Morales (eds), Tectonic shifts. Haiti since the earthquake, Sterling, VA, 18-22. 
Otto, I.M., D. Reckien, C.P.O. Reyer, R. Marcus, V. Le Masson, L. Jones, A. Norton and O. Serdeczny, 2017: Social vulnerability to climate change. A review of concepts and evidence, Regional environmental change 17, 1651-62.

Parker, G., 2014: Global crisis. War, climate change and catastrophe in the seventeenth century, New Haven.

Peterson, N., and K. Broad, 2016: Climate and weather discourse in anthropology. From determinism to uncertain futures, in S.A. Crate and M. Nuttall (eds), Anthropology and climate change: From encounters to actions, London.

Pleşu, A., 2018: Destinul ca țesătură, Dilema Veche 773, 13-19, available at www.dilemaveche.ro/sectiune/tema-saptamanii/ articol/destinul-ca-tesatura-1, accessed 20 December 2018.

Radivojevic, M., B.J. Roberts, E. Pernicka, Z. Stos-Gale, M. Martinon-Torres, T. Rehren, P. Bray, D. Brandherm, J. Ling, J. Mai, H. Vandkilde, K. Kristiansen, S.J. Shennan and C. Broodbank, 2018: The provenance, use and circulation of metals in the European Bronze Age. The state of the debate, Journal of archaeological research, at https://doi.org/10. 1007/s10814-018-9123-9.

Ribeiro, A., 2018: Death of the passive subject. Intentional action and narrative explanation in archaeological studies, History of the human sciences 31(3), 105-21.

Riede, F., 2014: Towards a science of past disasters, Natural hazards 71, 335-62.

Riede, F., 2017: Past-forwarding ancient calamities. Pathways for making archaeology relevant in disaster risk reduction research, Humanities 6, 79.

Riede, F., 2018: Deep pasts- deep futures. A palaeoenvironmental humanities perspective from the Stone Age to the Human Age, Current Swedish archaeology 26, 13-30.

Riede, F., P. Andersen and N. Price, 2016: Does environmental archaeology need an ethical promise?, World archaeology 48, 466-81.

Robinson, E., and F. Riede, 2018: Cultural and palaeoenvironmental changes in Late Glacial to Middle Holocene Europe. Gradual or sudden?, Quaternary international 465, 159-61.

Roberts, N., R.M. Fyfe, J. Woodbridge, M.-J. Gaillard, B.A.S. Davis, J.O. Kaplan, L. Marquer, F. Mazier, A.B. Nielsen, S. Sugita, A.-K. Trondman and M. Leydet, 2018: Europe's lost forests. A pollen-based synthesis for the last 11,000 years. Nature communications 8(716), DOI:10.1038/s41598-017-18646-7.

Roberts, P., C.S. Henshilwood, K.L. van Niekerk, P. Keene and A. Gledhill, 2016: Climate, environment and early human innovation. Stable isotope and faunal proxy evidence from archaeological sites (98-59ka) in the Southern Cape, South Africa, PLOS ONE 11(7), e0157408.

Shennan, S. (ed.), 1994: Archaeological approaches to cultural identity, London.

Shennan, S., 2004: Analytical archaeology, in J.L. Bintliff (ed.), A companion to archaeology, Oxford, 3-20.

Snow, C.P., 1998 (1959): The two cultures and the scientific revolution, Cambridge.

Sørensen, T.F., 2017: The two cultures and a world apart. Archaeology and science at a new crossroads, Norwegian archaeological review 50(2), 101-15.

Stanton, T.W., 2004: Concepts of determinism and free will in archaeology, Annales de antropología 38, 29-83.

Stephens, S., 1994: Situated knowledges and accountable scientific visions, Ethnos 59, 71-79.

United Nations, 2016: Climate change resilience. An opportunity for reducing inequalities, New York.

Von Wright, G.H., 1971: Explanation and understanding, London.

Weiss, H. (ed.), 2017: Megadrought and collapse. From early agriculture to Angkor, Oxford.

Wheatley, D., 1993: Going over old ground. GIS, archaeological theory and the act of perception, in J. Andresen, T. Madsen and I. Scollar (eds), Computing the past. Computer applications and quantitative methods in archaeology, Aarhus, 133-38.

Whewell, W., 1847: The philosophy of the inductive sciences. Founded upon their history. New edition, with corrections and additions, and an appendix, containing philosophical essays previously published, London.

Wylie, A., 2002: Thinking from things. Essays in the philosophy of archaeology, Berkeley, CA.

Wyrwoll, K.-H., 2012: How Aboriginal burning changed Australia's climate (11 January 2012), at https://theconversation. com/how-aboriginal-burning-changed-australias-climate-4454, accessed 11 January 2019. 